\title{
Happy Hours are a Godsend
}

\section{Dr. Krishna Pakala, Boise State University}

Krishna Pakala, Ph.D., is an Clinical Associate Professor at Boise State University, Idaho. His academic research interests include innovative teaching and learning strategies, use of emerging technologies, and mobile teaching and learning strategies.

\section{Dr. Diana Bairaktarova, Virginia Tech}

Dr. Diana Bairaktarova is an Assistant Professor in the Department of Engineering Education at Virginia Tech. Through real-world engineering applications, Dr. Bairaktarova's experiential learning research spans from engineering to psychology to learning sciences, as she uncovers how individual performance is influenced by aptitudes, spatial skills, personal interests and direct manipulation of mechanical objects.

\section{Samantha Schauer, Boise State University}

Samantha Schauer is a student at Boise State University, graduating in May 2020 with a Bachelor's degree in Mechanical Engineering and a minor in Applied Mathematics. Samantha works as an Undergraduate Research Assistant under Dr. Krishna Pakala. She is also actively involved in the Honors College, the Society of Women Engineers, and the Tau Beta Pi Engineering Honor Society. 


\title{
Happy Hours are a Godsend
}

\begin{abstract}
Office hours that happen in a virtual environment are called virtual office hours. This type of student-faculty interaction can be easily hosted from a faculty computer/mobile device/tablet. With an invitation, students can login to the online session and join their instructor and peers in a virtual space. Using mobile technologies, students can join virtual office hours from a variety of locations including a library, outdoors, on a commute ride home, while caring for children, eating dinner, and even while grocery shopping. Virtual office hours allow for more flexibility of student-faculty interaction. They are an alternative to traditional office hours. This type of student-faculty interaction helps increase students' trust in the teacher's care of their learning. This paper describes the design and implementation of virtual office hours for courses in the thermal-fluid sciences (Thermodynamics, Fluid Mechanics, and Heat Transfer). Further, it reports on students' learning experiences.
\end{abstract}

\section{Introduction}

A virtual environment can provide students and faculty with more flexibility in meeting time, location, content delivery, and type of interaction. Traditional office hours are historically not well attended [1]. Additionally, an instructor's office can only hold up to three students. Virtual office hours have no limit on attendance and can also provide a low-stakes platform for discussions, allowing students to better articulate their thought process. Successful virtual sessions are dependent on thoughtful design. Questions that encourage deeper thinking, problemsolving, and critical analysis are essential to student engagement and to the success of a virtual session. To re-conceptualize virtual office hours as more informal settings where student-student, student-content, and student-faculty interactions are enhanced, one engineering instructor and a co-author of this paper, Dr. Krishna Pakala, named them "Happy Hours". The title of this paper is inspired by an anonymous student comment from the course evaluations.

Happy Hours are extra help sessions hosted by an instructor and are held in replacement of traditional in-person office hours. Happy Hours are held twice a week, on the evenings before an in-person lecture. They are typically held around 8:00 pm in order to be available to the largest number of students. These hour-long virtual sessions allow all students to sign onto a shared virtual space, meaning that students can sign in from anywhere at their own convenience (Fig. 1). The instructor shares their iPad screen and communicates through a microphone, while students can communicate with the instructor and each other through instant messaging/microphone on the same platform. Happy Hours are conducted through the video chat platform Zoom, and prior to Fall 2018, the instructor used Blackboard Collaborate to facilitate the same experience. The instructor emails problems to students to be worked in the Happy Hour at least a day before the session. During the Happy Hour, students typically have time to work through practice problems individually, and the professor walks through the solution with the group so that students understand the proper approach and can ask questions on the components they found confusing. These sessions are also recorded and posted to YouTube so that students can revisit them when studying on their own time, and they are available to anyone who was not able to make the 
session due to time conflicts. These sessions were held for the following courses Thermodynamics, Fluid Mechanics and Heat Transfer.
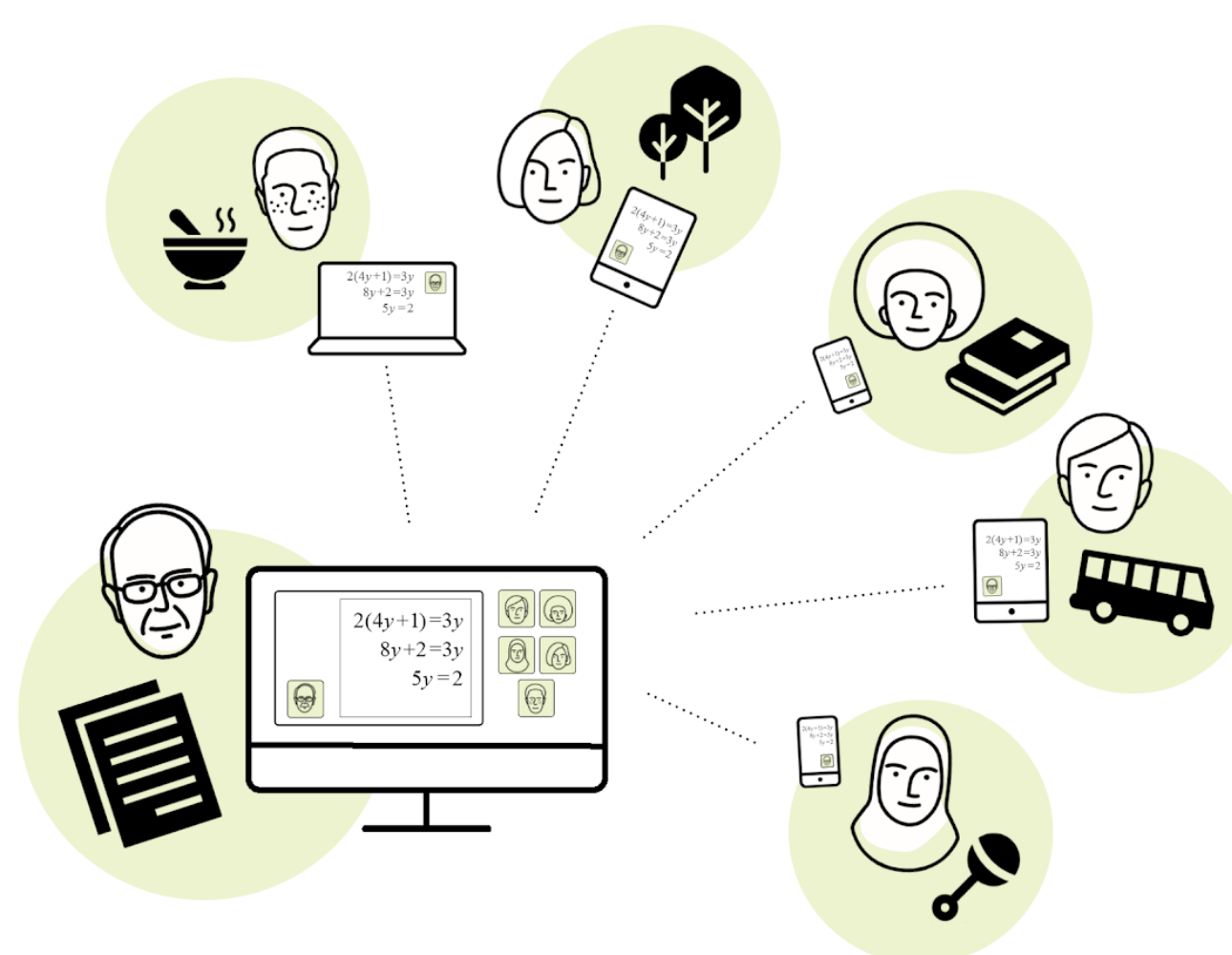

Figure 1. Graphical model of virtual office to demonstrate the adaptability of student schedules.

\section{Background}

As a relatively new way of student-faculty interaction, it is presumable that there is limited research regarding the design and implementation of non-traditional office hours. However, in reviewing the literature, it brings to light that non-traditional office hours are hosted in a variety of forms. Video conferencing can be utilized on multiple platforms such as FaceTime, Skype, Google Hangouts, and GoToWebinar [2], while some instructors opt to use social media and instant messaging platforms [3] instead. Virtual office hours can be hosted in a group video conference, such as those conducted by one of the authors of this study, or they can be arranged on an individual basis, more like traditional office hours but with the added convenience of being able to be held regardless of the location of both parties [4].

Currently, office hours are underutilized. Most studies have found that students do not take advantage of this type of interaction, and rather their communication with their instructor is infrequent and limited to formal occasions, such as in-person lectures [1]. The purpose of virtual office hours is to help break down those barriers and increase the availability of the instructor. In a study done in 2009, one instructor taught two different sections of a course: one utilizing only 
traditional office hours, and one section that also tested virtual office hours in the form of chatting over Facebook. In summary, it was found that students who participated in the virtual office hours were more comfortable and confident during in-class discussions [1]. Not only did students understand the material better, but their participation also improved the in-class environment as a result.

Virtual office hours are a proven effective method of communication for all course types, they can be implemented in in-person lectures, hybrid courses, or online courses. One instructor taught an online Thermodynamics course, while they traditionally teach in-person lectures. After implementing virtual office hours in their online course, they found that they are important and valued by students in both types of course instruction [5]. Online courses are typically challenging with a lack of student-faculty interaction, however virtual office hours can be utilized to bridge that gap and provide opportunities for students to ask and discuss questions.

Office hours have more benefits than gaining a deeper understanding of the course material. Through the attendance of office hours, whether traditional or non-traditional, students also can get to know their professors, which then makes students more comfortable and that relationship could grow into a mentor-mentee relationship as well. In a study done by Patrick Lowenthal to find the best way to increase student attendance at virtual office hours, he surveyed students about their intentions for attending these sessions. While most students attended sessions to learn the course material, requirements, and get questions answered, the primary reason students attended sessions was to get to know their professor [6].

With the increased use of technology in the lives of students, it is logical to carry that familiarity over to academia. Many traditional students have now grown up surrounded by technology (Net Gen), and many of them expect that technology be implemented into their learning experience [4]. By implementing a combination of in-person and technology-based office hours, professors are able to meet the needs of the traditional students who have grown up around technology, and the non-traditional students who tend to prefer in-person consultation.

One of the reasons that interaction with faculty is crucial to a student's learning experience is because it builds a mutual feeling of respect among all parties. It can be argued that the best educators do not lead with a sense of power, but rather they prove that they're invested in their students. By developing that positive, interpersonal relationship, it proves to the students that their professors believe in their capabilities and promotes a positive classroom atmosphere [4]. In a study involving 9 engineering schools, it was found that positive faculty-student interaction is significantly related to being satisfied with their major, and it increases the likelihood that that student holds an engineering job ten years in the future [7]. Virtual office hours are one effective way to increase the level of positive faculty-student interaction and a faculty's approachability.

Happy Hours are unique in comparison to other non-traditional forms of office hours for multiple reasons. Unlike interactions through social media platforms, Happy Hours are not a one-on-one interaction between a faculty member and a student, but rather they can hold the entire classroom in their virtual space. This form of virtual office hours is also held regularly twice a week, rather than as a form of test prep, such as those held by Patrick Lowenthal. Happy Hours are also a mix of pre-planned problems and student guided questions. Prior to the Happy Hour, the instructor sends out a set of problems to all students in the course so that students can view and start 
working on the problems before the meeting. At the start of each session, however, students are given an opportunity to bring up any questions that they have regarding the course. After that, students are free to ask questions throughout the session so that the Happy Hour is student focused, rather than acting as an additional lecture.

\section{Method}

This study reports on the design and implementation of virtual office "Happy Hours" for courses in the thermal-fluid sciences, such as Thermodynamics, Fluid Mechanics and Heat Transfer, taught at Boise State University. It also reports on students' learning experiences as described by the students involved in these subjects. All twenty-six courses had the same requirement that students were expected to attend a minimum of sixteen help sessions throughout the semester to earn 5\% of their grade. The sixteen-session requirement can be met by attending Peer Educator (PE) sessions, Happy Hours, or any combination of the two. The courses span three thermalfluid science courses (13 Thermodynamics courses, 9 Fluid Mechanics courses, 4 Heat Transfer courses) across five years and includes Spring, Summer, and Fall sessions, from Spring 2013 to Fall 2018. A manuscript reporting on the whole data set is under preparation.

This paper presents the analysis and findings of the student course evaluations for those enrolled in Heat Transfer, which represents 4 out of the 26 courses. The course was taught by one of the authors of this paper, Dr. Pakala, and IRB approval was obtained before conducting course evaluation analysis. This study was guided by the research question: How do students perceive Happy Hours experience regarding their learning?

The researchers utilized thematic coding, an approach used to analyze qualitative data. The research team particularly focused on two open-ended response questions from the whole evaluation set: "What barriers to learning, if any, did you experience in this course?", and "Which aspects of this course were most valuable to your overall learning experience?". The analysis was done to gauge whether students viewed Happy Hours as a hindrance or a benefit, and to what extent were those opinions held.

\section{Participants}

Across the four sections of Heat Transfer, there were 153 total students and 98.04\% (150) of them filled out the course evaluation. The course breakdown can be seen in Table 1.

Table 1. Course evaluation responses for Heat Transfer courses.

\begin{tabular}{|c|c|c|}
\hline & Course Enrollment & Course Evaluation Responses \\
\hline Fall 2018 & 49 & 47 \\
\hline Summer 2017 & 12 & 12 \\
\hline Spring 2017 & 51 & 51 \\
\hline Spring 2016 & 41 & 40 \\
\hline
\end{tabular}




\section{Study settings}

Peer Educator (PE) sessions are 75-minute help sessions hosted by a student who not only has already taken the course, but proved to be one of the top students their semester with a deep understanding of the material. They are hand selected for their position, and each semester there are typically one or two PEs who host 6 sessions each week. These sessions are held at a variety of times with the hope that students can fit at least one per week into their schedule. During these sessions, students can expect to study with their peers by working through practice problems, studying concepts for their exams, and asking questions of the PE. However, not everyone can commute to campus to attend these sessions due to family or work commitments.

\section{Data collection}

Course evaluations are distributed by the university for all courses each semester. The evaluation period is open for the last two weeks of a semester, closing the night before finals week. Periodically, reminder emails are sent to students who have not yet finished their evaluations to encourage them to complete the evaluations and to remind them of the importance of student feedback for the instructors and for the university. The instructor does not have access to course evaluation responses until after final grades are submitted and the grades are officially posted by the Registrar.

Student responses are entirely anonymous. The system only reports how many students completed the course evaluations and their responses. In order to encourage maximum participation and solicit feedback from the students, the instructor did offer an extra credit incentive to students who provided a screenshot of their survey completion. The screenshots do not include survey responses, they just show confirmation of their course evaluation submission. The extra credit incentive was for a bonus 25 points out of a total of 1000 possible quiz points, offering an extra $0.025 \%$ to the quiz portion of the total grade.

\section{Analysis}

In order to generate the data, the categories for thematic coding needed to be selected. To do that, two researchers analyzed the course evaluations for all four sections of Heat Transfer, which contained 150 student responses. Then the researchers analyzed both open-ended questions and created a list of the items mentioned the most in the responses. For the questions regarding barriers to students' self-perception of learning, there were 5 course aspects that were frequently mentioned: PE/Happy Hour sessions, course material, exams/quizzes, class structure, and personal reasons. Categories of "no barriers" and "miscellaneous" were also added to get a true representation of the data.

For the question asking about the course aspects that students found valuable to their learning, there were 5 categories that emerged as the most frequently mentioned: Happy Hours, PE sessions, class structure, extra resources, and the instructor. A category titled "miscellaneous" was also added to encompass the occasional comment that didn't fit in any of the other categories.

When conducting the thematic coding, the researchers went through every student response to both questions and recorded the number of times that each category was mentioned. This was 
done to get a full understanding of the data, as oftentimes the student responses mentioned multiple barriers or multiple valuable components in their comments.

In addition to the thematic coding, the researchers looked at the average Happy Hour attendance and number of views on the posted recordings for one randomly selected section of Heat Transfer. As the attendance at traditional in-person office hours tends to be quite low with very few students taking advantage of them, attendance at the instructor's Happy Hours is important to note.

\section{Findings}

After looking at the attendance at Happy Hours in one section of 49 students (Heat Transfer), it was found that the overall attendance ranged between 2 and 35 students (Table 2). In looking at the average attendance to Happy Hours compared with the number of students in the course, the average Heat Transfer session held $43 \%$ of the course.

Table 2. Happy Hour Attendance for Heat Transfer courses.

\begin{tabular}{|c|c|c|}
\hline Happy Hour Attendance & Number of Students & Percentage of Class \\
\hline Minimum & 2 & $4 \%$ \\
\hline Average & 21 & $43 \%$ \\
\hline Maximum & 35 & $71 \%$ \\
\hline
\end{tabular}

The cumulative data showing what students saw as components that aided in their learning can be seen in Figure 2. Happy Hours were by far the most popular response, collecting 32.88\% of the total student comments. They were followed by PE Sessions and Class Structure, collecting $22.37 \%$ and $18.72 \%$ of the comments, respectively. There is some uncertainty with this data. Many of the student responses that got sorted into "PE Sessions”, "Extra Resources” or "Instructor" category could be implying the benefit of Happy Hours without explicitly stating it. Many student responses mentioned how valuable "help sessions" were, and unless the comment specifically stated Happy Hours, those comments got sorted in the PE Session category. There also were a large amount of comments that generally mentioned the instructor going above and beyond, and that could be interpreted to mean their dedication to the students with the implementation of Happy Hours. While Happy Hours were the number one comment, it is possible that the actual percentage of student comments is a higher percentage. 


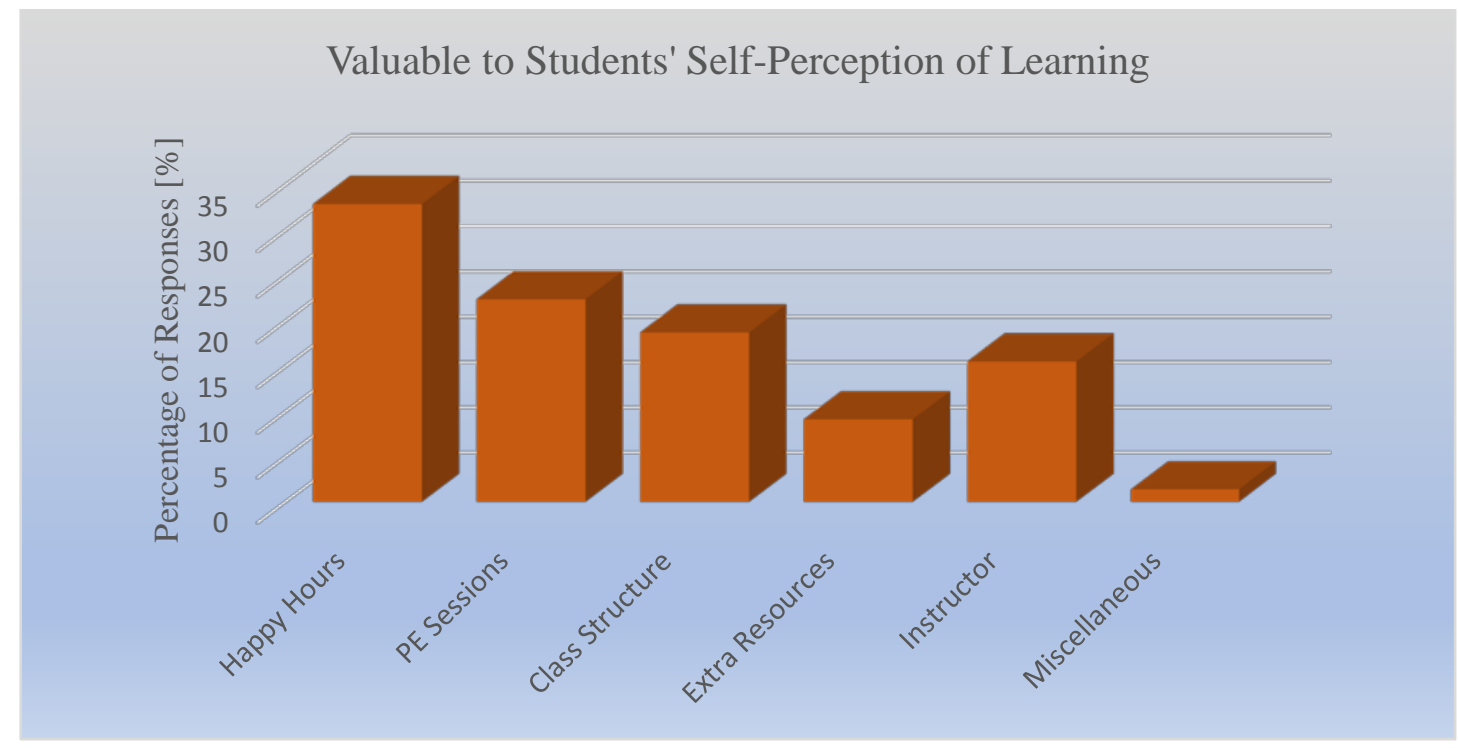

Figure 2. Percentages of student responses for Heat Transfer course components valuable to students' self-perception of learning.

Figure 3 depicts the thematic coding of student responses to what they found as barriers to their learning. Overwhelmingly, students reported that they had no barriers to learning, with 37.61\% of students reporting that they had no issues. The combination of PE sessions and Happy Hours was tied for the least mentioned component alongside Class Structure, each collecting 7.69\% of student responses. It is worthwhile to note that the majority of course evaluations that mentioned PE sessions and/or Happy Hours as a barrier to learning mentioned the fact that they were required to attend sessions for their grade. Those students found it difficult to find time to attend help sessions given their family and/or work situations.

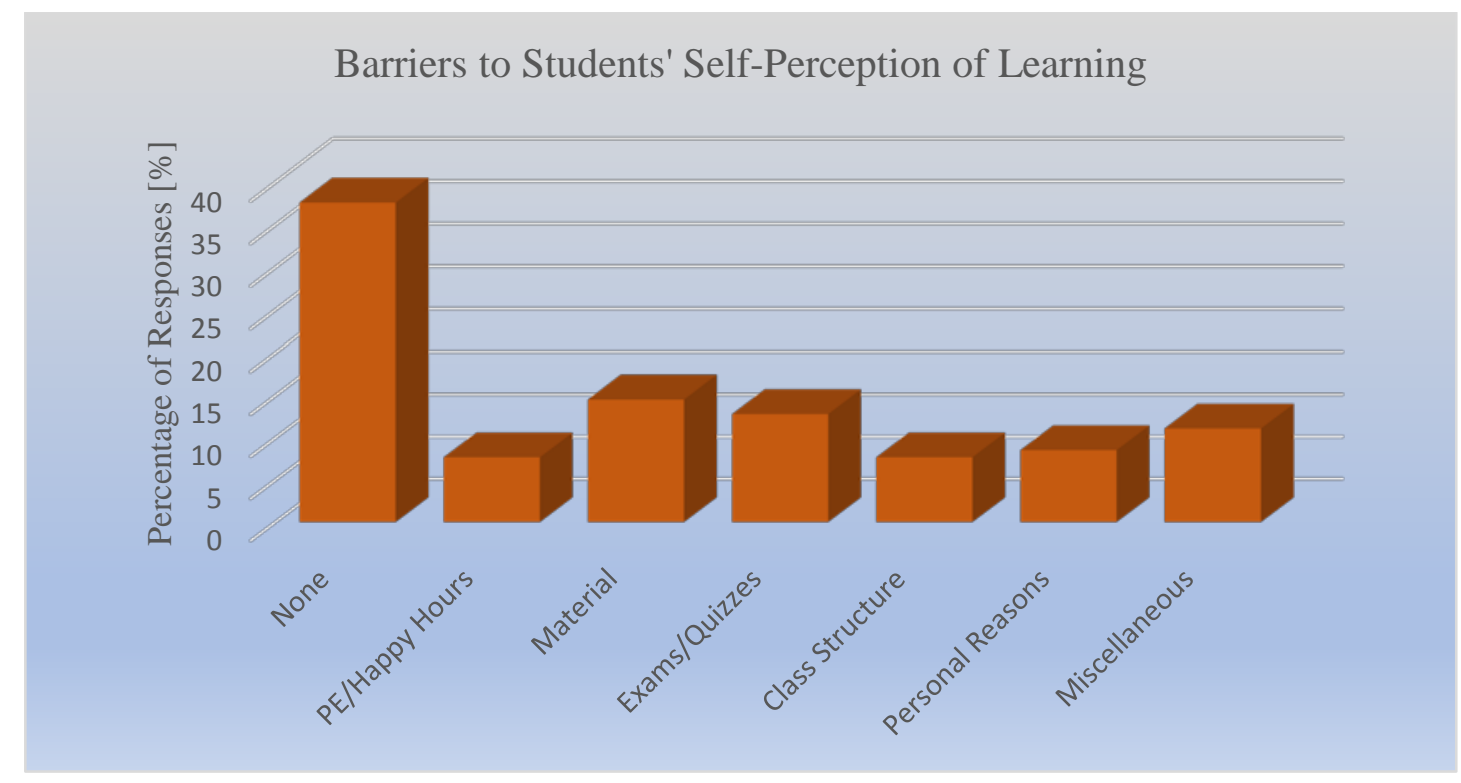

Figure 3. Percentage of Heat Transfer responses for barriers to students' self-perception of learning. 
Examples of student responses used in the thematic coding can be found in Table 3. Note that LA sessions are "Learning Assistant" sessions, which are synonymous with PE sessions. Help sessions were called LA sessions prior to the implementation of the Peer Educator program.

Table 3. Student responses from Heat Transfer course evaluations.

\begin{tabular}{|l|l|}
\hline $\begin{array}{l}\text { Which aspects of this course were most } \\
\text { valuable to your overall learning experience? }\end{array}$ & $\begin{array}{l}\text { What barriers to learning, if any did you } \\
\text { experience in this course? }\end{array}$ \\
\hline $\begin{array}{l}\text { "The happy hours were the most beneficial } \\
\text { part of the class. Having the extra work with } \\
\text { problems really helps improve understanding } \\
\text { of the concepts discussed in class, and allows } \\
\text { the instructor to work through more } \\
\text { complicated problems, that there would not be } \\
\text { time to do during class." }\end{array}$ & $\begin{array}{l}\text { "I wasn't able to attend any of the L.A. } \\
\text { sessions or happy hour sessions due to my } \\
\text { mork schedule and me having to provide for } \\
\text { on learning I had to do it by myself, which } \\
\text { wasn't a bad thing it just didn't allow me to } \\
\text { get the 5\% grade from the attendance." }\end{array}$ \\
\hline $\begin{array}{l}\text { "Happy Hours, this gave me time to do more } \\
\text { practice problems and ask any questions I had } \\
\text { during this time. There is no pressure and it is } \\
\text { purely for the students learning." }\end{array}$ & $\begin{array}{l}\text { "Attending 16 LA sessions was challenging. } \\
\text { Meek, and I struggled to make sure I could be } \\
\text { at the one session every week." }\end{array}$ \\
\hline $\begin{array}{l}\text { "The Happy Hours were the most valuable to } \\
\text { my learning experience. The fact that the } \\
\text { recordings were available at any time was } \\
\text { really helpful." }\end{array}$ & $\begin{array}{l}\text { "The happy hours and PE were hard for me to } \\
\text { make because of dates and times conflicting } \\
\text { with work. I mentioned it in the beginning of } \\
\text { the semester, but it could not be adjusted." }\end{array}$ \\
\hline $\begin{array}{l}\text { "The Happy Hours were a valuable tool in } \\
\text { understanding the methodology to accurately } \\
\text { apply the problem solving and it gives us the } \\
\text { opportunity to work together on a single } \\
\text { problem." }\end{array}$ & $\begin{array}{l}\text { "Trying to attend all of the extra activities that } \\
\text { they were needed to attend if a really good } \\
\text { grade was wanted." }\end{array}$ \\
\hline
\end{tabular}

In two of the semesters of Heat Transfer, Spring 2017 and Fall 2018, there was an additional quantitative question on the course evaluation. Students were asked to respond to the statement "Supplemental materials/resources provided by the instructor were extremely helpful (eg. YouTube Videos for Recitation and Lectures, Happy Hours)". Responses were given on a Likert Scale, with 1 corresponding to "strongly disagree", 3 corresponding to "neutral", and 5 corresponding to "strongly agree". Across both semesters, $99 \%$ of students responded with a 4 or a 5 , with an average score of 4.85 .

\section{Discussion and Conclusion}

This study was guided by the research question: How do students perceive Happy Hours experience regarding their learning? Thematic coding was used to analyze 150 students' qualitative course evaluations, across four sections of Heat Transfer. The research team 
particularly focused on two open-ended response questions from the whole evaluation set: "What barriers to learning, if any, did you experience in this course?", and "Which aspects of this course were most valuable to your overall learning experience?". The aim of this exploratory work was to add insights to the growing body of scholarly work on virtual student-faculty interaction and report on the design and implementation of non-traditional office hours, in this case, called Happy Hours. This work confirms the literature that non-traditional office hours are hosted in a variety of forms [2-4].

Further, findings from this study confirm that students do not take advantage of traditional office hours to the same extent as when student-instructor interaction is offered in a virtual space [1]. In the study reported here, the average attendance at Happy Hours was close to half of the class (43\%). In comparison to traditional office hours, this high level of attendance is nearly unheard of, especially given that a single office typically cannot hold more than three students at a time. There were 25 Happy Hours held in Fall 2018 and the views on the posted recorded sessions to YouTube ranged from 26 to 54 views per video with an average of 39 views per video.

The reviewed literature suggests that the purpose of virtual office hours is to help break down learning barriers and increase the availability of the instructor. Studies reveal that students who participate in virtual office hours are more confident in their learning of a new material [1]. Answering the research question of this study, it was also found that Happy Hours were by far the most popular indicator of helping in students' learning (32.88\% of the total student comments). In addition, many student responses mentioned how valuable "help sessions" were and how dedicated to their learning the instructor was. The last confirms findings from previous studies and adds more to the understanding of the multiple benefits of virtual office hours students not only feel more confident in gaining a deeper understanding of the course material, but they also appreciate their instructor's effort of ensuring students' learning [6,7].

In conclusion, this exploratory study supports the philosophy of meeting students where they are, meaning that there are students who are fluent with new technology and it is a matter of time until full integration of e-learning will take place in students' learning experiences, including virtual office hours. By implementing a combination of in-person and technology-based office hours, the needs of sophisticated college students can be met, for both traditional and nontraditional students.

\section{References}

[1] L. Li and J. Pitts, "Does It Really Matter? Using Virtual Office Hours to Enhance StudentFaculty Interaction", Journal of Information Systems Education, vol. 20, no. 2, pp. 175-185, 2009. [Accessed December 2018].

[2] D. Dickrell III, "Virtual Office Hours through Video Conferencing: Lessons Learned", in 120th ASEE Annual Conference \& Exposition, Atlanta, GA, 2013.

[3] D. Meyers, "The Impact of Virtual Office Hours on In-Class Participation", in AnnualMeeting of the American Educational Research Association, Chicago, IL, 2003. 
[4] R. Lillie and D. Wygal, "Virtual Office Hours (VOH) in accounting coursework: Leveraging technology to enhance an integrative learning environment", Journal of Accounting Education, vol. 29, pp. 1-13, 2011. Available: 10.1016/j,jaccedu.2011.10.002 [Accessed December 2018].

[5] D. Yang and K. Pakala, "Building an Effective Online Thermodynamics Course for Undergraduate Engineering Students", ASEE, 2017.

[6] P. Lowenthall, "Live Synchronous Web Meetings in Asynchronous Online Courses:

Reconceptualizing Virtual Office Hours", Online Learning Journal, vol. 21, no. 4, pp. 177-194, 2017. Available: https://olj.onlinelearningconsortium.org/index.php/olj/article/view/1285.

[Accessed 29 December 2018].

[7] "Faculty-Student Interaction (FSI): Learn More", Engaging Students in Engineering, 2019. [Online]. Available: https://www.engageengineering.org/fsi/whyitworks/learnmore. [Accessed: 24- Jan- 2019]. 